\title{
Bacteriological hazards of disposable bedpan systems
}

\author{
G. L. GIBSON ${ }^{1}$ \\ From the Bacteriology Laboratory, County Hospital, York
}

SYNOPSIS A system using disposable papier maché bedpans and urinals in hospital has advantages of ease of handling for the nurse and cleanliness for the patient. Disposal of the bedpans and their contents is by destruction and flushing to waste. Some bacteriological hazards of this process in the Haigh Sluicemaster and J.M.L. Clinimatic machines are assessed, particularly the dispersal of the ? contents in spray and aerosol during opening, closing, and running the machines. Various safety devices were tested and some deficiencies are discussed.

A major defect in the system is the need at present for a bedpan carrier or support which is not $\overrightarrow{\vec{\sigma}}$ disposable and requires cleaning and disinfection. Minor problems include ordering and storing $\circ$ bulky items, possibly the texture of the bedpans themselves, and perhaps the effect of the bulk of paper discharged into the sewage system.

At present the system seems unsuitable for use in infectious disease hospitals and has some deficiencies in use in general wards. The improvements suggested would greatly increase its acceptability which should then be completely re-assessed. To this end the examination of improved models using totally disposable bedpans is proceeding.

The provision of bedpans and urinals to hospital patients must depend on a system designed to offer to the patient a non-infectious, socially clean, ergonomically acceptable article. It must offer to the nurse a simple, effective, safe and inoffensive method of providing the patient with such an article and of disposing of its contents.

The object of this investigation was to assess the bacteriological hazards, potential and actual, of the processing of disposable papier maché bedpans and urinals and to consider some other factors involved in their use.

'Present address: Public Health Laboratory, Bridle Path, York Road, Leeds 15

Received for publication 6 November 1972.
A large number of bedpan destructors were ava able in the hospital groups served, but tests were concentrated on the most modern available models $\stackrel{2}{\approx}$ of the Haigh Sluicemaster and J.M.L. Clinimatic $\stackrel{\square}{\triangle}$ series. Two examples of each type were tested(TableI). $\overrightarrow{\vec{O}}$

For the investigations, faecal and urine specimens $\frac{9}{3}$ were used and aerobic faecal organisms estimated, as indicating fresh recent environmental contamination. MacConkey agar plates were used to culture and identify these organisms except in air sampling tests when blood agar was substituted. Incubation was aerobic at $37^{\circ} \mathrm{C}$ overnight.

Surface colony counts were arbitrarily divided as follows: $-=$ no growth, $\pm=1-4$ colonies per 0

\begin{tabular}{|c|c|c|}
\hline & Sluicemaster & Clinimatic (Mark V) \\
\hline Manufacturers & Haigh (Hygiene) Ltd, Ross-on-Wye & J.M.L. (Burnley) Ltd, Burnley \\
\hline Capacity & Four bedpans or 4 urinals or mixture & Three bedpans or 4 urinals or mixture \\
\hline Action & Rotating plate with blades in base of chamber & Rotating plate with blades in base of chamber \\
\hline Water supply & $\begin{array}{l}\text { Seventy-litre tank. Pumps } 40 \text { litres to centre lid, } \\
\text { bottom of chamber, drain and vent in } 120 \mathrm{sec}\end{array}$ & Ninety-litre tank, pumps 45 litres to centre lid in $115 \mathrm{sec}$ \\
\hline Drainage & Through grilles to drain box and waste & Through grilles to drain box and waste \\
\hline Lid & $\begin{array}{l}\text { Top opening, rear hinged, foot pedal operation, } \\
\text { no positive closure }\end{array}$ & $\begin{array}{l}\text { Top opening, rear hinged, hand operated, no positive } \\
\text { closure }\end{array}$ \\
\hline Safety devices & $\begin{array}{l}\text { Insufficient water, drainage blockage, prevent } \\
\text { opening when running }\end{array}$ & $\begin{array}{l}\text { Insufficient water, drainage blockage, prevent } \\
\text { opening when running }\end{array}$ \\
\hline
\end{tabular}

Table I Summary of technical details of models tested 


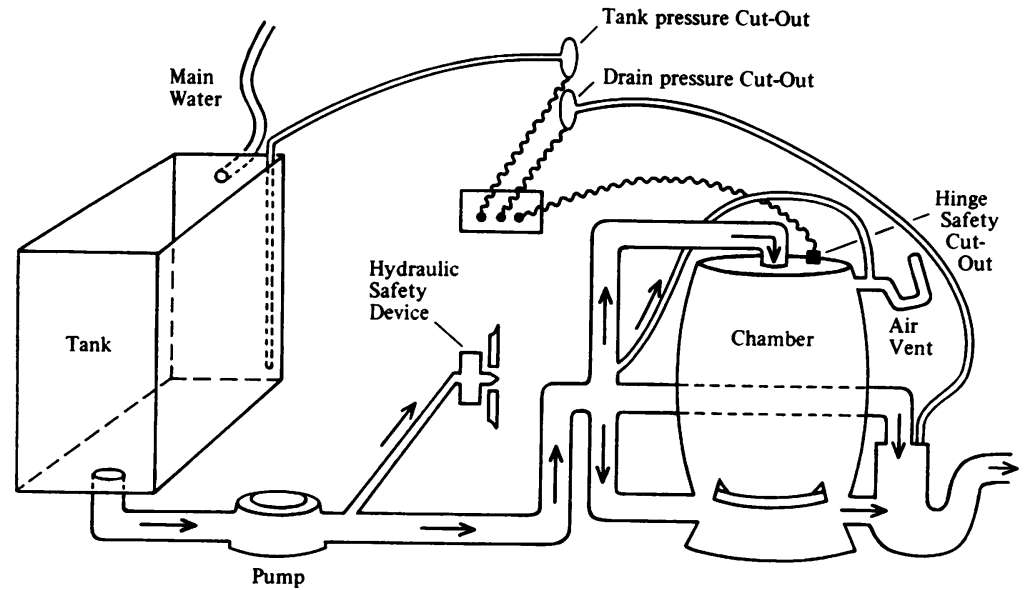

Fig. 1 Diagrammatic representation of Haigh Sluicemaster.

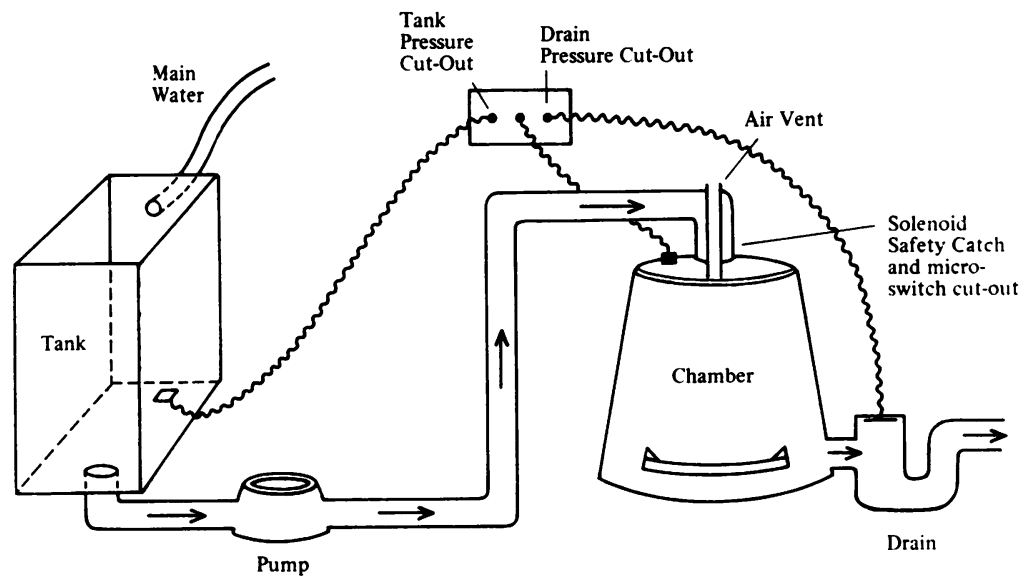

Fig. 2 Diagrammatic representation of Clinimatic mark $V$.

plate, $+=5-19$ colonies per plate, $++=20$ colonies-confluent growth.

Test loads in the machines varied but the maximum was not exceeded. Codes are as follows: $F=$ faeces in bedpan, $\mathbf{U}=$ urine in urinal or bedpan, $\mathrm{E}=$ empty bedpan or urinal.

\section{Haigh Sluicemaster}

EXPERIMENT 1: AIR SAMPLING

A base level was first established and was low (average 10 organisms/c $\mathrm{ft}$ ) in the vicinity of the destructor. Variations occurred during the use of the sluice room by staff but never reached more than minor levels and the normal use of the destructor did not significantly alter the base level. No evidence of escape of faecal organisms in quantity into the air of the environment could be demonstrated.
This bears out the findings of Blowers and Puckrin (1962) who, however, used cellulose wadding doused in a broth culture of $E$. coli to simulate faeces in their tests on a very early Clinimatic machine.

EXPERIMENT 2: OPENING THE LID

This was tested at the end of a cycle as it was thought that splashing, aerosol formation, and the escape of organisms would be most likely at this time. The lid of the Sluicemaster operated by a foot pedal has a coarse, sudden action when opened and there are visible water particles and aerosol release.

Eight MacConkey agar plates were attached to the upper surface of the lid by adhesive tape. They overhung the rim exposing the agar surface downwards toward the chamber. They were numbered clockwise from the hinge.

The lid was jerked open and the plates were 
removed. The results of five tests on different days are shown in Table II. It will be seen that contamination is light and does not conform to any pattern.

\begin{tabular}{|c|c|c|c|c|c|c|c|c|c|c|}
\hline \multicolumn{3}{|c|}{ Contents } & \multicolumn{8}{|c|}{ Growth on MacConkey Agar Plates } \\
\hline$F$ & $\boldsymbol{U}$ & $E$ & 1 & 2 & 3 & 4 & 5 & 6 & 7 & 8 \\
\hline 2 & 1 & - & - & - & - & - & - & - & - & - \\
\hline 1 & 3 & - & - & - & + & + & \pm & - & + & - \\
\hline 1 & - & 3 & - & - & - & \pm & - & - & - & - \\
\hline 2 & 1 & - & + & \pm & - & $\overline{-}$ & \pm & - & + & + \\
\hline 2 & 1 & - & - & - & - & - & - & - & - & - \\
\hline
\end{tabular}

Table II Haigh Sluicemaster on opening lid

EXPERIMENT 3: CLOSING THE LID

This was tested in two different circumstances: 'pre run' and 'post run'.

The condition of the rim of the chamber was noted in each case. Plates were attached as in experiment 2 and the lid was closed using the foot pedal. The closing action was also abrupt and visible water particles and aerosol were produced. The results are shown in Table III. It will be seen that considerable contamination can result from shutting the lid, especially immediately after a run when the rim of the opening is wet.

\section{EXPERIMENT 4: ESCAPE OF ORGANISMS \\ DURING RUN}

For this purpose a ring of 11 MacConkey agar plates was placed and numbered clockwise round the rim of the lid. They remained throughout the run. The results are shown in Table IV. A noticeable variable was that on some occasions when the cycle was started or shortly thereafter the lid would momentarily jump very slightly open. This appeared to be due to the bedpans or urinals being forced or thrown against the inside. Where this occurred is indicated in Table IV and most of the results showing contamination appear when this has happened.

A further confirmation of these results was made $\mathrm{O}$ by using a strong solution of methylene blue in lieu of faeces in the top bedpan of a four-bedpan load, running the machine until completion of cycle and

\begin{tabular}{|c|c|c|c|c|c|c|c|c|c|c|c|c|}
\hline \multicolumn{3}{|c|}{ Contents } & \multicolumn{8}{|c|}{ Growth on MacConkey Agar Plates } & \multirow{2}{*}{$\begin{array}{l}\text { Condition of Rim of } \\
\text { Chamber }\end{array}$} & $\begin{array}{l}\text { Before or after } \\
\text { Run }\end{array}$ \\
\hline$F$ & $\boldsymbol{U}$ & $E$ & $I$ & 2 & 3 & 4 & 5 & 6 & 7 & 8 & & \\
\hline 4 & - & - & \pm & \pm & + & - & - & - & - & \pm & Cleaned & B $€$ fore \\
\hline 2 & 2 & - & - & - & - & - & - & - & - & - & Dry/clean & Before \\
\hline 2 & 2 & - & $\therefore$ & - & - & - & - & + & - & - & Cleaned & Before \\
\hline 1 & 3 & - & - & - & - & + & + & - & - & - & Clean/dry & Before \\
\hline 1 & 1 & 2 & $+t$ & \pm & \pm & - & - & $+t$ & ++ & ++ & Dirty/dry & Before \\
\hline 3 & - & - & $+t$ & $+t$ & ++ & $+t$ & $t+$ & ++ & $+t$ & ++ & Dirty/wet & Before \\
\hline 1 & 2 & 1 & ++ & $+t$ & + & ++ & ++ & $+t$ & ++ & + & Dirty/wet & Before \\
\hline 2 & 1 & - & + & + & + & ++ & $t+$ & ++ & ++ & + & Dirty/wet & Before \\
\hline 3 & 1 & 0 & $t+$ & ++ & ++ & $+t$ & $+t$ & ++ & $+t$ & ++ & Wet/clean & Before \\
\hline- & - & - & ++ & $+t$ & ++ & $+t$ & ++ & ++ & ++ & $+t$ & Wet & After \\
\hline- & - & - & $t+$ & $+t$ & + & + & +1 & ++ & ++ & ++ & Wet & After \\
\hline- & - & - & ++ & ++ & ++ & ++ & ++ & ++ & $t+$ & $+t$ & Wet & After \\
\hline- & - & - & ++ & ++ & ++ & ++ & ++ & $+t$ & ++ & $+t$ & Wet & After \\
\hline- & - & - & + & + & + & + & + & + & + & + & Wet & After \\
\hline- & - & - & $t+$ & $+t$ & $t+$ & ++ & ++ & $+t$ & ++ & ++ & Wet & After \\
\hline- & - & - & $+t$ & ++ & ++ & ++ & ++ & ++ & $+t$ & ++ & Wet & After \\
\hline
\end{tabular}

Table III Haigh Sluicemaster on shutting lid

\begin{tabular}{|c|c|c|c|c|c|c|c|c|c|c|c|c|c|c|}
\hline \multirow[t]{2}{*}{ Lid Jump } & \multicolumn{3}{|c|}{ Contents } & \multicolumn{11}{|c|}{ Growth on MacConkey Agar Plates } \\
\hline & $F$ & $U$ & $E$ & 1 & 2 & 3 & 4 & 5 & 6 & 7 & 8 & 9 & 10 & 11 \\
\hline- & 2 & 1 & - & - & - & - & - & - & - & - & - & - & + & + \\
\hline- & 2 & 2 & - & - & - & - & - & - & - & - & - & - & \pm & \pm \\
\hline- & 3 & 1 & - & - & - & - & - & - & - & - & - & - & \pm & \pm \\
\hline- & 3 & 1 & - & - & - & - & - & - & - & - & - & + & - & $\overline{-}$ \\
\hline- & 1 & 1 & 2 & - & - & \pm & - & - & - & - & - & - & - & \pm \\
\hline- & - & - & - & - & - & $\overline{-}$ & - & - & - & - & - & - & - & $=$ \\
\hline- & 2 & 2 & - & - & - & - & \pm & - & - & - & - & - & - & - \\
\hline- & 2 & 1 & - & - & - & - & $\overline{-}$ & - & - & - & - & - & - & + \\
\hline+ & 1 & 2 & 1 & - & - & + & ++ & + & + & - & - & - & + & ++ \\
\hline+ & 1 & 3 & - & + & - & - & \pm & - & \pm & + & \pm & \pm & \pm & + \\
\hline+ & 2 & 2 & - & - & - & - & \pm & - & - & - & $\overline{-}$ & - & $=$ & - \\
\hline+ & 1 & 3 & - & - & - & + & + & + & \pm & ++ & ++ & + & ++ & +1 \\
\hline+ & - & 4 & - & - & - & - & - & - & - & - & - & - & ++ & - \\
\hline+ & 2 & 1 & - & + & + & + & - & + & ++ & ++ & $+t$ & ++ & - & + \\
\hline
\end{tabular}

Table IV Haigh Sluicemaster test during run 
then opening and closing the lid. A large sheet of white disposable paper towelling was held vertically around the top of the cabinet during opening and closing and one was placed over the top of the cabinet during the actual runs. Obvious patterns of splashes showed clearly that an operator's clothing could be contaminated.

EXPERIMENT 5: TO ESTIMATE THE ESCAPE OF ORGANISMS ON OPENING THE LID DURING A TEST RUN

In spite of the safety devices fitted it was possible to lift the lid manually while the machine was in action quite sufficiently to allow an obvious spray of water, faeces, and papier maché to emerge. This was demonstrated repeatedly and the heavy contamination was obvious.

The result was again confirmed using methyleneblue and the widespread results of this can be seen in Fig. 3 which shows splashing reaching the wash basin, cupboard, wall, and even the paper hand towels above the basin.

\section{EXPERIMENT 6: ESCAPE OF ORGANISMS FROM} VENT

Repeated testing by holding a MacConkey agar plate $1 \mathrm{~cm}$ from the mouth of the vent pipe during closing, opening, and running failed completely to demonstrate any organisms escaping onto the plate during a normal cycle. Indeed the current of air in the vent is almost entirely inwards to the chamber during normal running.
EXPERIMENT 7: SWABBING OF VISIBLY CONTAMINATED SITES

\section{The outside of the machine}

The top of the machine and lid were often found visibly contaminated but little was grown unless the contamination was fresh and wet. The rim of the chamber was a simple and fruitful source of common faecal organisms and was generally wet.

\section{Interior of casing}

This was little contaminated and only dried fragments of papier maché could be found. No growth was obtained by simple swabbing, plating on blood agar plates, and incubating aerobically at $37^{\circ} \mathrm{C}$. However, when fragments were dropped into Robertson's cooked meat broth, incubated overnight at $37^{\circ} \mathrm{C}$ and then plated out on blood agar and incubated aerobically and anaerobically overnight at $37^{\circ} \mathrm{C}, 7 / 16$ specimens yielded coliforms, enterococci, or, in one case, proteus. No clostridia were recovered even after prolonged incubation.

\section{The vent pipe}

This was dismantled into three pieces and some faecal organisms were obtained on three of five occasions from the proximal section. No growth was obtained more distally at any time by simple aerobic techniques.

The pressure differential at the pipe end as measured by a column of water was never more than a few milimetres. In simple tests this pressure sufficed to

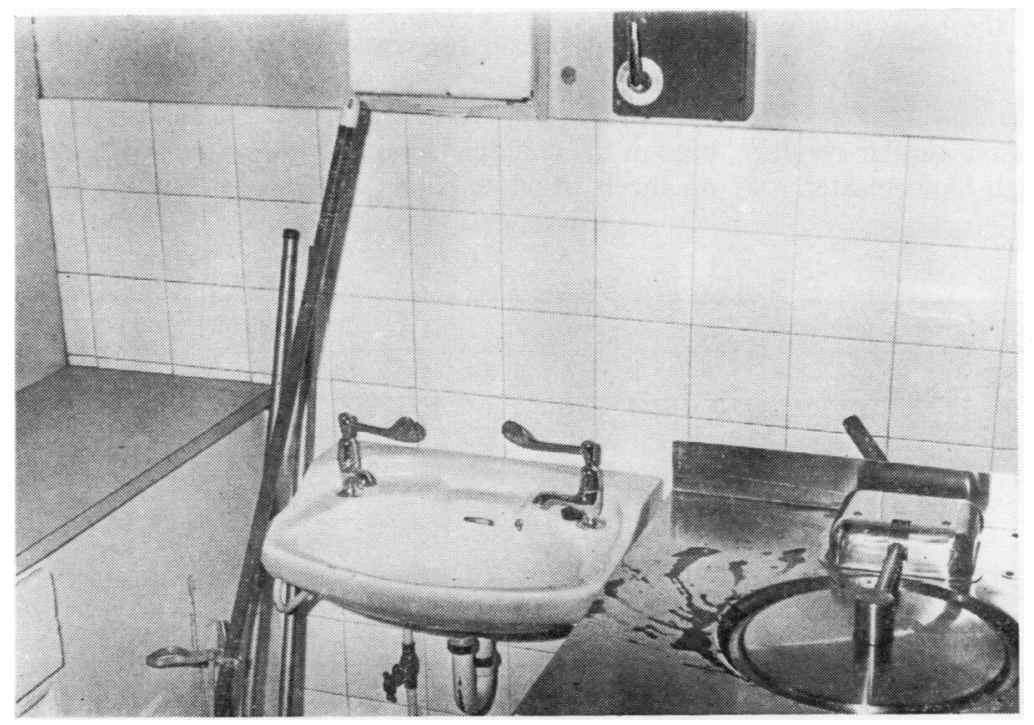

Fig. 3 Sluicemaster. Methylene blue splashed across wash basin, wall, cupboard, and towel holder, due to opening lid during run. 


\begin{tabular}{|c|c|c|c|c|c|c|c|c|c|c|c|c|c|c|c|c|c|}
\hline \multicolumn{3}{|c|}{ Contents } & \multicolumn{13}{|c|}{ Growth on MacConkey Agar Plates } & \multirow{2}{*}{$\begin{array}{l}\text { Condition of Rim } \\
\text { of Chamber }\end{array}$} & \multirow{2}{*}{$\begin{array}{l}\text { Before or } \\
\text { After }\end{array}$} \\
\hline$F$ & $U$ & $E$ & 1 & 2 & 3 & 4 & 5 & 6 & 7 & 8 & 9 & 10 & 11 & 12 & 13 & & \\
\hline 3 & - & - & - & - & - & - & ++ & - & - & - & - & - & - & - & - & Dirty & Before \\
\hline 2 & - & 2 & - & - & - & - & ++ & - & - & - & - & - & - & - & - & Dirty & Before \\
\hline 1 & - & 3 & - & - & - & - & - & - & - & - & - & - & - & - & - & Dirty & Before \\
\hline 3 & - & 1 & - & - & - & - & - & - & - & - & - & - & - & - & - & Clean & Before \\
\hline 4 & - & - & - & - & - & - & - & - & - & - & - & - & - & - & - & Dirty & After \\
\hline 4 & - & - & - & - & - & - & - & - & - & - & - & - & - & - & - & Wet & After \\
\hline 3 & - & - & - & - & - & - & - & - & - & - & - & - & - & - & - & Dirty & Before \\
\hline 3 & - & - & - & - & - & - & - & - & - & - & - & - & - & - & - & Dirty & Before \\
\hline 2 & - & $\overline{-}$ & $=$ & $\overline{-}$ & - & - & ++ & - & - & - & - & - & - & - & - & Clean & Before \\
\hline 2 & - & $\bar{z}$ & I & $=$ & $\bar{z}$ & $=$ & \pm+ & $=$ & $\overline{-}$ & $=$ & $=$ & $=$ & - & $\overline{-}$ & - & $\begin{array}{l}\text { Wet } \\
\text { Dirty }\end{array}$ & After \\
\hline 3 & - & - & - & - & - & - & - & - & - & - & - & - & - & - & - & Dirty & $\begin{array}{l}\text { After } \\
\text { After }\end{array}$ \\
\hline
\end{tabular}

Table V Clinimatic on shutting lid

inflate but not to expand a fingerstall placed over the vent. When the drain was completely blocked using a valve in the drainpipe there was still no increase in pressure measurable at the vent, as escape from the lid of the chamber was impossible to control. When alteration in design includes a well fitted, positiveclosing lid, escape of pressure from the vent may become a more significant factor. At present air flow tends to be inwards rather than outwards during the cycle.

\section{Clinimatic}

The same tests were carried out as with the Sluicemaster but the details of the sampling techniques had to be varied in some experiments because of differences in construction. In the tests on the lid and chamber opening, the MacConkey agar plates were used first in a similar manner attached to the fibreglass lid cover. Nine plates surrounded the sides and front, and a further four were suspended along the back. They were numbered from the back plate on the right hand side clockwise 1-13.

EXPERIMENT 1: AIR SAMPLING

Air sampling of the sluice room gave similar results to those carried out with the Haigh Sluicemaster.
EXPERIMENT 2: OPENING THE LID

The lid is opened by hand and is easily controlled ? with a smooth action with no sudden abrupt movement.

On four occasions on two machines no growth whatever was obtained by this method.

\section{EXPERIMENT 3: CLOSING THE LID}

As before tests were carried out before and after a run and the condition of the rim of the chamber was noted.

The results can be seen in Table $\mathrm{V}$ and show onle occasional heavy contaminaion on plate 5 which wa in the central front position.

\section{EXPERIMENT 4: ESCAPE OF ORGANISMS} DURING RUN

The 13 plates in the same position as before were left in place throughout an entire cycle. The results of ten such tests can be seen in Table VI and demonstrate only negligible contamination throughout by this method.

Confirmatory tests were done using methylene blue in the chamber load and observing the staining on sheets of white paper, as described above.

\begin{tabular}{|c|c|c|c|c|c|c|c|c|c|c|c|c|c|c|c|c|c|c|}
\hline \multicolumn{3}{|c|}{ Contents } & \multicolumn{16}{|c|}{ Growth on MacConkey Agar Plates } \\
\hline $\boldsymbol{F}$ & $\boldsymbol{U}$ & $\boldsymbol{E}$ & 1 & 2 & 3 & 4 & 5 & 6 & 7 & 8 & 9 & 10 & 11 & 12 & 13 & 14 & 15 & 16 \\
\hline 4 & - & - & - & - & - & - & - & - & - & - & - & - & - & - & - & - & - & - \\
\hline 2 & 2 & - & - & - & - & - & - & - & - & - & - & - & - & - & - & - & - & ++ \\
\hline 1 & - & 3 & - & - & - & - & - & - & - & - & - & - & - & - & - & - & - & - \\
\hline 3 & - & 1 & - & - & - & - & - & - & - & - & - & - & - & - & - & - & - & - \\
\hline 1 & - & 4 & - & - & - & - & - & \pm & \pm & - & - & \pm & - & - & - & - & - & - \\
\hline 2 & - & 2 & - & - & - & - & - & $\bar{z}$ & $=$ & - & - & $\overline{-}$ & - & - & - & - & - & - \\
\hline 3 & - & - & - & - & - & - & - & - & - & - & - & - & - & - & - & - & - & - \\
\hline 2 & - & - & - & - & - & - & - & - & - & - & - & - & - & - & - & - & - & - \\
\hline 3 & - & - & - & - & - & - & - & - & - & - & - & - & - & - & - & - & - & - \\
\hline 3 & - & - & - & - & - & - & - & - & - & - & - & - & - & - & - & - & - & - \\
\hline
\end{tabular}

Table VI Clinimatic test during run 
EXPERIMENT 5: THE ESCAPE OF ORGANISMS ON OPENING THE LID DURING A TEST RUN It was possible to lift the lid manually while the machine was in action quite sufficiently to allow a visible spray of water, faeces, and papier maché to emerge. This was demonstrated repeatedly and heavy contamination was obvious on the MacConkey agar plates.

\section{EXPERIMENT 6}

Repeated testing by holding a MacConkey agar plate $1 \mathrm{~cm}$ from the mouth of the vent pipe during closing, opening, and running failed completely to demonstrate any organisms spraying onto the plate during normal free running.

\section{EXPERIMENT 7: SWABBING OF VISIBLY CON-} TAMINATED SITES

\section{The outside of the machine}

The top of the machine was often found visibly contaminated especially under the overhang of the lid. The lid itself was rarely contaminated. Little was grown from any site unless the contamination was fresh and wet. The rim of the chamber was a simple and fruitful source of common faecal organisms and was generally wet.

\section{Interior of casing}

This was heavily contaminated and dried faeces and papier maché could be seen on most of the interior surfaces and covers of the parts of the apparatus. The hinge mechanism and surrounding pipe work were the most heavily contaminated areas. Faecal organisms could on occasions be recovered from these sites by simple aerobic cultivation and heavy growths of coliforms, enterococci, and Clostridium welchii were obtained using Robertson's cooked meat broth. Twelve of 16 such specimens yielded coliforms, and 12 out of 16 yielded Clostridium welchii.

\section{Vent pipe}

Swabs of the interior failed to yield positive cultures on six out of six occasions although small pieces of papier maché adhering to the underside of the fibreglass lid cover over the mouth of the vent pipe showed that the chamber contents could on occasions be expelled through the vent. Culture of such material on two occasions aerobically and anaerobically was totally unproductive.

Tests of pressure differential using a finger stall over the end of the vent pipe gave similar results to those on the Haigh machine. Again blockage of the drain did not materially increase the vent pipe pressure due to escape of air around the lid.
As the sampling techniques which were employed in the foregoing experiments were less suitable to the Clinimatic machine than to the Haigh a number of modifications and additional tests were attempted.

It was decided to use MacConkey agaroid cylinders both as 'pressure contacts' against relevant surfaces and as 'settle plates'. An alternative tried was to use Uricult plastic plates of MacConkey agar in both these roles but, although readily available and very simple to use separated from the Uricult bottle top, they did not give such satisfactory growth within 18 hours, and are of course, more expensive than the MacConkey agaroids made in this laboratory. They do, however, present a reasonable alternative to agaroids for this type of investigation and have the advantage of being easily returned to the container and reunited with the screw top and transported without damage.

Before a run was begun, the agaroid was pressed against four sites at the corners of the underside of the lid, a slice of agaroid being removed after each pressure. These tests were named 'pre-run lid' and were numbered clockwise 1-4.

Four positions on the rim of the chamber were tested also by pressing the agaroid cylinder against them and similarly four sites were tested on the cabinet top round the opening of the chamber.

Six agaroid slices were placed on the cabinet top in these four positions and also on either side of the hinge.

The lid was then slammed shut.

Six agaroid slices on these same positions were left during the course of a cycle of the machine to monitor the run itself. These tests appear as 'run' in the results.

Following the run the same tests were repeated as were done before the run. These were designated 'after-run', in each case.

The condition of the machine was noted before the tests began.

Results can be seen in Table VII.

The heavy contamination of the rim both before, and especially after, a run can be seen, together with some evidence of contamination of the top of the cabinet and the escape of organisms during shutting the lid.

\section{Estimation of Destructive Capacity}

Both machines were well able to cope mechanically with the maximum permitted load and indeed the reduction by the manufacturers of the Clinimatic of a recommended four bedpans to three bedpans seemed a counsel of overcaution. However, both machines frequently exhibit the bumping phenomenon and this is particularly evident when fully laden. 


\begin{tabular}{|c|c|c|c|c|c|c|c|c|c|c|c|c|c|c|c|c|c|c|c|c|c|c|c|c|c|c|}
\hline \multicolumn{3}{|c|}{ Contents } & \multicolumn{24}{|c|}{ Growth on MacConkey Agaroids } \\
\hline & & & \multicolumn{18}{|c|}{ Before the Run } & \multirow{2}{*}{\multicolumn{6}{|c|}{ Run }} \\
\hline & & & \multicolumn{4}{|c|}{ Lid } & \multicolumn{4}{|c|}{ Top } & \multicolumn{4}{|l|}{$\operatorname{Rim}$} & \multicolumn{6}{|c|}{ Slam } & & & & & & \\
\hline$F$ & $\boldsymbol{U}$ & $E$ & 1 & 2 & 3 & 4 & 1 & 2 & 3 & 4 & $l$ & 2 & 3 & 4 & 1 & 2 & 3 & 4 & 5 & 6 & 1 & 2 & 3 & 4 & 5 & 6 \\
\hline 3 & - & 1 & - & - & - & - & \pm & - & - & - & - & $+t$ & ++ & - & - & - & - & - & - & - & - & - & ++ & - & - & - \\
\hline 2 & - & 1 & - & - & - & - & + & + & + & + & + & + & + & + & - & - & - & - & - & - & - & - & - & - & - & - \\
\hline 3 & - & 1 & - & - & - & - & - & - & - & - & ++ & - & - & $+t$ & - & - & - & - & - & - & - & - & - & - & - & - \\
\hline 2 & 1 & 1 & - & - & - & - & - & - & - & - & \pm & \pm & \pm & \pm & - & - & - & - & - & - & - & - & - & - & - & - \\
\hline 1 & 1 & 2 & - & - & - & - & - & - & - & - & ++ & - & \pm & ++ & \pm & - & - & - & - & - & - & - & - & - & - & - \\
\hline 3 & - & 1 & - & - & - & - & - & - & - & - & ++ & - & - & ++ & $\overline{-}$ & - & - & - & - & - & - & + & - & - & - & - \\
\hline 3 & 1 & - & - & - & - & - & - & - & - & - & ++ & ++ & ++ & ++ & + & + & + & + & + & + & - & + & - & - & - & - \\
\hline 3 & - & 1 & - & - & - & - & - & - & - & - & ++ & ++ & ++ & ++ & + & + & - & - & - & - & - & - & - & - & - & - \\
\hline 3 & - & 1 & - & - & - & - & \pm & \pm & \pm & \pm & - & ++ & ++ & ++ & - & - & - & - & - & - & - & - & - & - & - & - \\
\hline 3 & - & 1 & - & - & - & - & \pm & - & \pm & - & - & - & - & $+t$ & + & \pm & - & \pm & \pm & \pm & \pm & ++ & \pm & - & - & - \\
\hline
\end{tabular}

Table VII Clinimatic tests using agaroids

In addition to the load of papier maché and faeces a reasonable quantity of toilet paper is easily disposed of. Occasionally the shiny hard type of paper is found wrapped around the blades of either machine at the cycle end, but is always eventually broken up and dispersed. The appropriate slipper-shaped covers for bedpans constructed of rough grey cardboard are easily dealt with, but shiny paper bags of the kind often used as bedpan covers can be found undestroyed after a cycle.

Certain articles are not destroyed and may interfere with the free running of the machine, eg, incontinence pads, sanitary towels, hard shiny paper, polythene, plastics, rubber, cloth, glass, and metal.

\section{Discussion}

The first major disadvantage of the disposable bedpan systems is the need at present for a carrier or support for the bedpan. This is of plastic or fibreglass and is not disposable. Its disinfection is a serious problem and the need for it is a basic defect in the whole system, although with care it can be done. We have found boiling or the use of cetrimide/chlorhexidene adequate for the task, as did Dafforne (1963). Indeed Schwabacher (1963) found after swabbing with $1 \%$ cetrimide that fibre-glass carriers compared favourably with steel bedpans when tested for contamination, due to their lack of a turned-over rim. She also found that the carrier was never touched by the patient's buttocks nor was it soiled by excreta. We cannot confirm this latter opinion and find considerable contamination in practice and that cleaning is not always done properly. Examples of carriers returning for further use in a faecally contaminated condition can be seen all too frequently. Separate carriers can, of course, be used for individual patients, but this requires large numbers of them, with increased storage space and for this reason was advised against by Dafforne (1961).
Secondly, the machines allow the escape of live organisms into the environment during their use and $\vec{A}$ thus constitute a hazard, particularly as there is no $\vec{~}$ disinfection by heat or chemicals involved in the 음 process. In the report to the Public Health Laboratory Service of the Working Party on Haemodialysis ${ }_{D}$ Units (1968), it was recommended that for the $\frac{0}{7}$ destruction of viruses either a steam jet washer or boiler was necessary or failing that, faeces from $₹$ patients undergoing haemodialysis should be $\vec{\varphi}$ covered by a suitable phenolic disinfectant before $\omega$ being discharged to waste. The importance of the liquid state of the stool itself in the spread of infection was noted by Parker (1954) and stressed by Rowe, Giles, and Brown in 1969 in the spread of salmonellosis. The pulping process in the destructor $\stackrel{\circ}{\mathbb{D}}$ involves the formation of a finely divided wet pulp $\stackrel{\varrho}{\Rightarrow}$ and spray and aerosols are produced. This mixture of stool and paper while not the same in all respects as a naturally produced liquid stool, particularly in bacterial content, does have similar characteristics and may well have similar dangers.

A disadvantage of papier maché bedpans themselves 0 as compared with those of steel lies in their relatively rough surface which may actually damage thin or $\delta$ tender skin over pressure points. The surface has improved recently but the point is still valid. Minor 을 disadvantages include recurring revenue costs, and ordering, delivery, and storage of bulky items

Problems may arise in the disposal of large amounts of pulp into the sewage system. Adequate local $\mathrm{N}$ drainage is necessary (Payne and Lorenzato, 1970) $N$ and the weight of pulp discharged by a major hospital $\mathrm{N}$ can be considerable. The quality of sewage works 0 effluent may be affected but as papier maché is bio- 0 degradable in spite of fillers and binding agents, it is $\frac{2}{\Phi}$ possible that a cleaner, more friable product may be $\stackrel{\odot}{+}$ achieved at the end of sewage treatment. In an average 0 community the additional weight of solids in sewage attributable to total use in hospitals of 


\begin{tabular}{|c|c|c|c|c|c|c|c|c|c|c|c|c|c|c|c|c|c|c|c|}
\hline \multicolumn{18}{|c|}{ Growth on MacConkey Agaroids } & \multirow{4}{*}{$\begin{array}{l}\text { Comments on } \\
\text { Lid }\end{array}$} & \multirow{4}{*}{$\begin{array}{l}\text { Condition of } \\
\text { Rim }\end{array}$} \\
\hline \multicolumn{18}{|c|}{ After the run } & & \\
\hline \multicolumn{4}{|c|}{ Lid } & \multicolumn{4}{|c|}{ Top } & \multicolumn{4}{|l|}{$\operatorname{Rim}$} & \multicolumn{6}{|c|}{ Slam } & & \\
\hline$I$ & 2 & 3 & 4 & 1 & 2 & 3 & 4 & 1 & 2 & 3 & 4 & $I$ & 2 & 3 & 4 & 5 & 6 & & \\
\hline- & $+t$ & ++ & $+t$ & \pm & ++ & ++ & + & ++ & ++ & ++ & $+t$ & - & - & - & - & - & - & Jump \& splash & Wet \\
\hline- & - & - & - & + & + & + & + & + & + & + & + & - & - & - & + & \pm & - & No jump & Wet \\
\hline- & - & - & - & \pm & - & - & - & ++ & \pm & - & \pm & - & - & - & - & $\overline{-}$ & - & No jump & Clean \\
\hline- & - & - & - & - & - & - & - & ++ & ++ & ++ & ++ & - & - & - & - & - & - & Jump & Clean \\
\hline- & - & - & - & - & - & - & - & ++ & - & - & ++ & \pm & + & \pm & - & - & - & Jump & Dirty \\
\hline \pm & - & - & - & - & \pm & - & - & ++ & - & - & ++ & $\overline{-}$ & \pm & $\overline{ \pm}$ & \pm & \pm & \pm & Jump & Dirty \\
\hline$\overline{-}$ & - & - & - & - & $\overline{-}$ & - & - & ++ & ++ & ++ & $+t$ & + & + & + & + & + & + & Shudder & Dirty \\
\hline- & - & - & - & + & - & - & + & ++ & $+t$ & ++ & $+t$ & ++ & ++ & ++ & - & - & \pm & Shudder & Dirty \\
\hline- & - & - & - & - & + & - & \pm & ++ & ++ & ++ & ++ & - & - & - & - & \pm & $\overline{-}$ & Shudder & Wet \\
\hline- & - & - & - & \pm & \pm & - & - & \pm & ++ & ++ & $+t$ & - & - & - & - & $\overline{-}$ & - & No jump & Clean \\
\hline
\end{tabular}

Table VII Clinimatic tests using agaroids-continued

disposable bedpans should not exceed $3 \%$, which is within the normal range of variation expected in sewage solids (Mozley, 1972).

Any estimation of the value of a system must consider alternatives to it. Disposable bedpan systems exist because of difficulties, costs, and defects in other systems. With only cold water, normal electric power, and reasonable drainage, they can answer a problem well and must have obvious advantages in new hospitals where steam is not available at ward level. They probably are no more risky in use than non-disposable bedpans subject to disinfection by hot water in washer-disinfectors as these are often slow to heat up and inadequate in action. They are much less expensive in capital outlay than mainsteam 'washer sterilizers' and are probably as safe in general wards as other systems not involving a sterilizing cycle in a properly closed vessel. Their use is certainly more acceptable to nurse and patient than a situation in which bedpans are sluiced, washed, and soaked in antiseptic. It would not be possible, however, to recommend the use of the existing system in infectious disease units.

Measures to improve the present systems are being actively pursued. The most important of these is the introduction of completely disposable bedpans, and provisional estimates of a test of 1000 of these are very favourable. Alterations to existing machines must include a positively closinglid as well as other minor modifications and they must be adapted to destroy the slightly heavier totally disposable bedpan. Such a machine provided to the author in prototype by one manufacturer has proved so far to do this reliably and safely over several months with a cycle time of 100 seconds to deal with two bedpans.

The tests of the modified destructor, totally disposable bedpans, and other devices indicate at this stage a much improved outlook for the disposable bedpan system and further tests are proceeding.

I wish to thank the engineering staff of York County Hospital and the nursing staff of the orthopaedic wards for their help. I am grateful to $\mathrm{Mr}$ N. Spence and $\mathrm{Mr}$ J. Foley of the Infection Control Laboratory, Clifton Hospital, York, for technical help, and to Mrs S. Paxton for clerical assistance.

This work was supported by a research grant from the Department of Health and Social Services.

\section{References}

Blowers, R., and Puckrin, J. (1962). Disposal bedpans: a study of a possible bacteriological hazard. Mth. Bull. Minist. Hlth Lab. Serv., 21, 235-236.

Dafforne, J. H. (1961). Disposable bedpans and urinals: a report on early experiences with the Vernaid system. The Hospital, $57,687-690$.

Dafforne, J. H. (1963). Disposable bedpans and urinals: a third article. The Hospital, 59, 209-212.

Mozley, A. (1972). Personal communication.

Parker, M. T. (1954). The spread of some bowel infections from human sources. Roy. Sanit. Inst. J., 74, 847-855.

Payne, R., and Lorenzato, A. (1970). Bedpan disposal units. In Hospital Drainage and Sanitation. Report to the Department of Health and Social Security. HMSO, London.

PHLS Working Party (1968). Infection risks of haemodialysis. Some preventive aspects. A report. Brit. med. J., 3, 454-460.

Rowe, B., Giles, C., and Brown, G. L. (1969). Outbreak of gastroenteritis due to Salmonella virchow in a maternity hospital. Brit. med. J., 3, 561-564.

Schwabacher, H. (1963). Disposable bedpans: further 'studies of a possible bacteriological hazard'. Mth. Bull. Minist. Hlth Lab. Serv., 22, 136-139. 